\title{
Feeling differently: Approaches and their politics
}

Laughing out loud at a funeral. Feeling depressed when you are elected 'employee of the year'. Empathizing with police during a protest. Displaying anger when others tell jokes. Feelings which do not conform to expectations can be problematic in a number of ways. To onlookers, they can be shocking, irritating or awkward, while the one enacting such feelings can feel embarrassed or excluded. If everyone but you is laughing, you are-for at least that moment-not part of the group. ${ }^{1}$ Such an experience might be gratifying, intended as open resistance to the prevalent norm or to common sense. Perhaps you did not want to applaud the joke. Purposefully rejecting the ways others display or enact a feeling might even endow you with a sense of dignity or pride. If shared feelings are viewed as forming and maintaining social ties - an issue addressed especially in approaches to the emotions that emphasize cultural patterns -, then not having them can outwardly signal both social exclusion and the contestation of norms. But even those feelings we have 'privately' can be experienced in this way, as we carry with us an awareness of how we are 'supposed' to feel. The fact that we often feel differently than expected thus calls for an inquiry into the wider social and spatial processes that support prevalent norms and their contestations. Who can afford to be happy in a particular setting or to show that they are not? Which social and spatial configurations foster conforming or dissident feelings?

These questions lead to a second set of issues which arises when feelings counter expectations. You're entering a bar, where everyone seems to be cheerful. But maybe the atmosphere embraced by others as joyful makes you melancholic. And maybe your melancholia ensues from your particular memories evoked by this specific place or what makes up this atmosphere-say, the celebration of a friend's new baby when you have just had a miscarriage, or a sense that this is the kind of place where 'white folks' bond, and you will never be fully included. Feeling differently as a response to atmospheric spaces is not only related to norms but also indicative of processes of subjectification and their social conditions, as writings emanating from psychoanalysis and cultural anthropology as well as both feminist engagements with emotions and recent discussions of affect have highlighted. Affects and emotions subjectify us, and they do so in concert with social and spatial conditions: they 'put you in your place'. Conversely, such felt dimensions of subjectification can also be regarded as coconstitutive of the very conditions at play: maybe it is their joy that makes you depressed. This also signals the complexity of felt difference, which can modulate with a change of context that is

\footnotetext{
${ }^{1}$ Drawing on Arlie Hochschild, Sara Ahmed (2010: 41) uses the term 'inappropriate affect' to describe such experiences.
}

not always easy to perceive.

This opens up a third line of investigation, where feeling differently is viewed in the context of the continuous variation of affects. From such a perspective, feeling is always, at least to a certain extent, feeling differently. Think of a worker in the service industries who is awarded a prize for her contribution to the company's achievements and is proud of it. Yet, perhaps this feeling of pride does not quite strengthen her sense of belonging to the corporation, but, rather paradoxically, aggravates a feeling of alienation. In addition to the fluidity and thus built-in ambiguity of feelings, this perspective brings into focus the singularity of affects as they result from complex worldly encounters. "[T]here are necessarily as many kinds of pleasure, pain, love, hatred, etc., as there are kinds of objects whereby we are affected", reasons Baruch Spinoza (1996: Part 3, Prop. 56, 170). Each feeling, in this understanding, varies with the kind of object it springs from in the moment of an encounter in a specific spatial setting. Perhaps it is this funeral, in this room, with the memories evoked by a certain arrangement of flowers and with its particular constellation of ritualised mourning, evocation of existential loss and a relative's melodramatic performance which makes you laugh. To the extent that each objectencounter differs from others, all attempts at normalisation of feeling can be seen as traversed by an ongoing, irreducible differing of feeling, the feeling differently which subsists within all feeling.

These scenarios illustrate the variety of angles from which 'feeling differently' can be approached. In doing so, they also highlight that engaging different aspects of feeling differently entails distinctive frames and concepts - with particular analytical and political consequences. Do we focus on the power of norms and feeling rules or on the forces of subversion and excess? Is our unit of analysis a culture or a body, a subject or an event? And do we as researchers relate to the phenomena studied as impartial observers or as politically (and affectively) invested actors? Feeling differently seems to be a particularly potent theme for exploring the tensions among different approaches to such issues - as well as their multiple interconnecting threads. In particular, this theme invites reconsideration of some of the basic assumptions that have undergirded conceptual debates, and kept them apart.

For instance, conceptual debates around feelings, affects and the emotions have revolved to a large extent around the question of whether feelings reproduce social orders or disturb them. On one end of the spectrum are rules-based and practice-oriented approaches, which highlight the extent to which emotional experiences and expressions are informed by a shared grammar of emotion words and patterns that pervades specific cultural contexts. On the other end, psychoanalytical and affect-theoretical approaches emphasize the variability and inherently indeterminate 
or excessive nature of affect. It has long seemed difficult to even bring these divergent perspectives into conversation with each other. Their respective proponents have frequently avoided engaging the others, except to criticise and delegitimise them. ${ }^{2}$

The main thrust of this themed issue aims at exploring the middling grounds and intersections between such heterogeneous approaches, without seeking to gloss over conceptual, analytic and political tensions. In particular, the articles, and this introductory essay, seek to bring out the importance of social and cultural norms without reducing emotional life to their mere reproduction - and without either neglecting or overemphasising the autonomy of affect and its potential for disruption. The themed issue thereby picks up recent debates that have begun to move more strongly across research traditions - also bringing into relief their unique strengths (e.g. Anderson, 2014; Bondi, 2014; Gould, 2009; Grossberg, 2010). The focus on feeling differently running through the contributions advances such engagement by inviting nuanced investigations of the relations between the norms structuring feelings and the subversion of such norms, considering also affective dynamics that exceed the play between norms and subversion. On the one hand, in relation to rules-based approaches, this focus challenges culturalist assumptions about the pervasive power of emotional conventions, as it brings to light precisely those cases where emotions do not fit. On the other hand, however, engaging ways of feeling differently also contests strong claims around the singular and excessive nature of affective phenomena, which upon closer inspection rarely turn out to be independent from the learned and scripted patterns against which they emerge as variations or deviations.

Thus moving across heterogeneous approaches also entails reconsidering the very terminology used to talk about feelings, emotions and affects. While some authors have advocated clearcut distinctions between these terms, attributing them to different (physiological, personal, social) registers (e.g. Shouse, 2005), others have favoured more fluid understandings. Especially the notion of 'feelings' - which as an analytic concept bears less discursive baggage than 'emotion' and 'affect' - has been invoked in approaches that evade, or explicitly interrogate, binary conceptions (e.g. Sedgwick, 2003). With its "double meaning, tactile plus emotional" (Sedgwick, 2003: 17), signifying touch while also invoking 'feeling rules' (Hochschild, 1979), it enables multiple points of entry for the discussion. This is why we have chosen to favour 'feelings' as a heuristic term here.

However, combining heterogeneous approaches should not be seen as an end in itself. We also need to ask: which are the particular epistemological and political projects animating different routes into the study of feeling? Which kinds of differences do these strands engage, how do they frame them, and what might be their effects? To tackle these questions we will first outline how prominent approaches to feelings have engaged feeling otherwise. Introducing the contributions to this issue, we will then consider how the optic of 'feeling differently' serves to reassemble this broader study of feelings. As we will discuss towards the end, this also enables a fresh perspective on the political ramifications different approaches to researching feelings have-also beyond the academy.

\section{Approaches to feelings and their takes on feeling differently}

The three lines of enquiry sketched out in the opening paragraphs highlight, in turn, the exclusionary as well as selfassertive effects of breaching norms; the complex interplay between atmospheres and subjectifications; and the continuous variation and excess of affect. These dimensions of feeling differently indicate how the topic lends itself to connecting divergent strands of research initiated by what some have called an emotional or affective turn in a range of humanities and social science disciplines, including history, sociology, anthropology, cultural geography and cultural and media studies (see Gregg and Seigworth, 2010; Lorimer, 2008; Plamper, 2015). While the notion of disregarding norms or habits picks up on rules-based and practice-theory approaches, the issue of subjectification invokes especially psychoanalytical engagements, as the concept of continuous variation invites affect-theoretical perspectives. These strands differ greatly due to their distinctive disciplinary genealogies as well as their wider epistemological projects. To begin unpacking how the focus on 'feeling differently' can still foster cross-cutting discussions among them, it seems useful to review briefly how each of them has framed relations between norms and difference.

Rules-based approaches focus primarily on the power of emotional conventions, only at times touching upon their violation. While within this line of research 'emotionology' concentrates on the display rules a society promulgates for discrete emotions (Stearns and Stearns, 1985), research on 'feeling rules' (Hochschild, 1979), 'emotional regimes' (Reddy, 2001) and 'emotional communities' (Rosenwein, 2006) strongly criticises the notion that there are 'display rules' for a fixed set of 'basic emotions'. These approaches do not strictly separate the experience of feeling from its expression and thus give language a particularly central role in shaping emotion - even leading to suggestions that emotions can be considered a kind of discourse (Lutz and Abu-Lughod, 1990). They therefore emphasise repertoires or even speak of emotional 'cultures' or 'styles'. With their focus on language and meaning, all these variants of rules-based approaches run the risk of reproducing mind-body dichotomies. This is the case even where they seek to show how emotional standards vary across time and space, for example concerning the extent to which anger was viewed as acceptable (see Althoff, 1998; Briggs, 1970; Hollan, 1988). If these studies engage with difference in feelings, this difference is of a collective nature-the difference of one group or society from another, or sometimes also the difference of one space from another. ${ }^{3}$ This, however, offers no explanation for why someone might diverge from the norm within a collectivity or a particular setting. The predominant assumption has been that everyone there shares the same emotional grammar.

Similar tendencies can be spotted in approaches based on practice theory. Characterised by their use of terms such as 'affective' or 'emotional practices' (Burkitt, 1997; Reckwitz, 2016; Scheer, 2012; Wetherell, 2012), 'habitus' (Holt et al., 2013) or even more specifically 'emotional habitus' (Illouz, 2007; Gould, 2009), these approaches reveal their indebtedness to Pierre Bourdieu's or to other versions of practice theory. Though they seek to overcome the mind-body, subject-object dichotomies which have haunted rules-based approaches, norms and social conventions still remain central, as emotions are viewed as embodied in habits and routines. 'Doing emotion' is seen as part of a continual process of learning or training as part of a social group and in a particular space. Again, the notion of shared emotional grammar can make it seem difficult to explain how a habit can be broken to produce a different feeling. This problem is mitigated somewhat when this approach draws more strongly on the performativity framework based in speech-

\footnotetext{
2 See for instance the debate between Ruth Leys (2011) and William E. Connolly
} (2011) in Critical Inquiry; see also Sharp (2009).

${ }^{3}$ On spatially specific emotional styles, see Gammerl (2012); on the distinction between work and leisure spaces, see Hochschild (1979). 
act theory, for then it can address the issue of when emotional performances fail. ${ }^{4}$ This could be considered a form of 'feeling differently' or 'failing to feel correctly'. Furthermore, it should not be forgotten that the habitus itself can be a source of resistance to rapidly changing societal norms, as Bourdieu's notion of the 'hysteresis effect' suggests, generating feelings that no longer 'fit'. But when these analyses focus on the continual reproduction of a specific habitus through emotions as practices, they can hardly attend to the emergence of ways of feeling differently and their effects.

Investigations using non-representational approaches to feeling and affect focus on exactly such emergent, contingent and excessive dimensions (see Anderson and Harrison, 2010; Clough and Halley, 2007; Gregg and Seigworth, 2010; Massumi, 2002; Thrift, 2007). They seek to shift from engagements with the formative force of discourses, social and cultural rules or habits to a view on affect as autonomous movement or intensity ensuing from interactions and encounters between bodies, or among bodies and their environment (e.g. Bissell, 2015; Wylie, 2005). Whether they draw on psychologists (e.g. Sylvan Tomkins), neuroscientists (e.g. António Damásio), the philosophies of Baruch Spinoza as well as Gilles Deleuze and Félix Guattari, or on psychoanalysis, phenomenology, feminist and queer theory, these various strands of research tend to have in common a concern with virtuality and becoming, in relation or in contradistinction to what actually is. A focus on feeling differently thus seems to pervade, and even be constitutive of, these perspectives. Rather than restricting their empirical analysis to observable phenomena, affect-theoretical approaches moreover seek to address emergent capacities and their effects. They view this openness of affect, its lack of a fixed object or-to use the phenomenological term-of intentionality, as generative of intensities that may become an engine for progressive politics (see e.g. Amin and Thrift, 2013; Sedgwick, 2003; Timm Knudsen and Stage, 2015). In particular feminist, queer and critical race theorists have highlighted the political potential springing from feelings and affective relations that rupture or trouble gendered, heteronormative and racist power formations (e.g. Lim, 2007; Puar, 2007). On the other hand, affect theorists have also posited social formations of power as operating themselves through visceral affective registers (Anderson, 2014), opening up new insights into the technological and bodily levels at which power operates, as distinct from the semiotic levels of the social and cultural. ${ }^{5}$ Post-operaist theorists and material feminists connect an engagement with affective encounters back to the specific feeling rules implied by different subject positions in the context of immaterial and gendered labour, considering the surplus value as well as the suffering this generates (e.g. Dowling et al., 2007; Gutiérrez-Rodriguez, 2010).

Psychoanalytic approaches, finally, have a long tradition of scrutinising the vicissitudes of feelings in relation to difference. They draw on a variety of authors and concepts, from Sigmund Freud's and Melanie Klein's discussions of positive and negative affect in relation to subject formation to John Bowlby's and Donald Winnicott's accounts of affective attachments and subject-space relations or Jacques Lacan's ruminations around existential anxiety and desire. Broadly speaking, psychoanalytic approaches highlight how unconscious dimensions of feelings go beyond the manifest content of written sources, images or interview data, but are still

\footnotetext{
${ }^{4}$ Cf. Eitler and Scheer (2009) and their discussion of 'trying emotion'. Reddy (2001) bases his framework for a history of emotions on speech-act theory and also discusses the open-ended nature of such performances, putting his framework on the border between rules-based and practice-theory approaches we outline here.

${ }^{5}$ For critical discussions, see Barnett (2008); Grossberg (2010). For alternative approaches to the relations of semiotics and affect, see Brinkema (2014) and Hutta (2015)
}

closely interwoven with processes of meaning production - which are also of interest to practice- and rules-based approaches. They bring up various issues regarding feeling differently. In relation to subjects' feeling in or out of place, for instance, some authors focus on how "[f]eelings of repulsion and desire, of nervousness, elation and so on, contribute to distanciation, the avoidance of certain places and people, or conversely, attraction to place and to particular social milieu" (Sibley, 1999: 116). Scrutinizing the affective dimensions of powerful social norms and differences, other authors discuss traumatic 'archives of feelings', powerful affective attachments to optimism or happiness as well as the public circulation of such feelings (Ahmed, 2010; Berlant, 2011; Cvetkovich, 2003). Assuming a constitutive mismatch or difference between subjects' desires and external norms, several authors moreover view feelings as necessarily involving an 'abject' dimension (or Lacan's 'real') that haunts social and symbolic orders from its margins as constitutive outside (see e.g. Bondi, 2014; Braunmühl, 2012; Pile, 2010; Stavrakakis, 2010).

As this synopsis indicates, the different routes into an engagement with feeling differently are not entirely separate. Rather, multiple connecting threads run through them that can be further explored. Variants of all these approaches, for instance, in one way or another mobilise performative understandings, reflecting a broader interest in the 'doing' of feeling. References to cognitive psychology and neuroscience but also to phenomenology with its specific understanding of the corporeal as collapsing the distinction between the subject and its surroundings, the inside and the outside also pervade both affect theory and practice theory, as well as some rules-based approaches. Psychoanalysis has strong affinities with the effects of learning and culturally patterned actions, just as practice theory does, making it useful for discussing specific historical constellations. Finally, space-sensitive approaches have facilitated the cross-cutting of all these research strands (e.g. Anderson, 2014; Gammerl, 2012; Pile, 2010). A persistent challenge in articulating these approaches resides in the distinctive ways in which levels of meaning, semiotics and culture on the one hand and viscerality and physiology on the other hand are brought into play. As binary oppositions are becoming increasingly tired, however, endeavours to generate more nuanced understandings of their mutual relations are also proliferating (see Hutta, 2015). If a focus on 'feeling differently' thus assists in bringing out differences and connections among approaches, it can moreover inspire investigations that work within and across them, as we will now outline.

\section{Ways of feeling differently}

To stimulate discussions that traverse existent approaches to emotions, affects and feelings, we are suggesting a focus on 'feeling differently', in the adverbial form. Whereas 'feeling different' would place the emphasis on someone's experience of alterity in relation to a prevalent state, the adverbial form sets a focus on varying modes or ways of feeling. We thus seek to spotlight emotional or affective processes, acts and events which both trouble and produce norms and subjectifications. This calls for appreciating open-ended affective or emotional processes and practices without neglecting the habituated and sedimented patterns, structures or regimes that such ways of feeling differently might emerge from, relate to or give rise to. Traversing the approaches just outlined-and signalling possibilities for new forms of exchange amongst them-we can identify at least three different ways of linking feeling and difference: research can examine, first, how feelings undermine established differences, second, how they themselves constitute difference, and, third, how feelings mark, intensify or naturalise differences. Engaging the particular questions that arise from these three perspectives on varying ways of 
feeling differently, we argue, de-emphasises contradictions between rules-based, practice-theory, non-representational and psychoanalytical approaches, and instead invites nuanced engagements with the ongoing constitution of norms and differences.

A first line of investigation focusses on how feelings undermine established differences, time and again breaking through the seemingly unshakable grid of social positions and identifications. From a rules-based perspective, such an understanding of feelings has been employed, for instance, to describe how empathy between the elites and the disenfranchised paved the way for universal human rights (Hunt, 2008) and humanitarian politics (Fassin, 2005). Others have discussed how feelings can break through the seemingly insurmountable distance between the present and the past, an argument proposed in discussions on nostalgia and queer temporalities (Love, 2007; Dinshaw, 2007; Newman, 2012).

Social movements and activisms in particular can support ways of feeling differently that challenge gendered, racialised and classrelated norms as well as prevalent understandings of what constitutes effective politics (Goodwin et al., 2001; Gould, 2009). Häberlen and Tändler (this issue) pick up on this debate by looking at political activists in 1970s West Germany who framed capitalism as implementing specific feeling rules and developed nonconforming emotional practices as a way to challenge these norms (see also Häberlen and Spinney, 2014; Brown and Pickerill, 2009), whereas Apostoli Cappello's contribution considers how activists of the Italian squatter movement emphasize emotional difference in contradistinction to both mainstream society and earlier social movements (see also Timm Knudsen and Stage, 2012). Such felt difference, as Ahmed's discussion of 'queer feelings' highlights, can also include "a discomfort which is generative": "[t]o feel uncomfortable is precisely to be affected by that which persists in the shaping of bodies and lives. Discomfort", she continues, "is hence not about assimilation or resistance, but about inhabiting norms differently" (Ahmed, 2014: 155, emphasis in original). ${ }^{6}$ This also signals that felt difference does not necessarily signal a refusal to identify with norms and the straightforward adopting of an oppositional stance. Bareither's paper in this issue argues that gamers who enjoy perpetrating gratuitous violence in the virtual space of online games are not merely enjoying the transgression of feeling rules but rather create an emotional space at the intersection of games and everyday life in which they can enact and experience humorous incongruities. Emotional dissent can be even more subtle: for example, Thajib's article in this issue discusses the ambivalences inherent in being a queer pious Muslim in Indonesia, showing how feeling narratives 'fold' subjects 'in and out of emotion norms'.

This leads to a second focus, which enquires more directly into how feelings constitute difference. Such a perspective has proven particularly fruitful in research on nationalism, which often draws on rules-based and practice-oriented approaches (Benei, 2008; Petersen, 2011) as well as on psychoanalysis (Parkinson, 2015). In her paper in this issue, Parkinson discusses the ressentiment of a defeated 'nation' being asked to change their feelings. She examines how Allied post-1945 efforts at 're-educating' the West German population construed the latter as adhering to totalitarian modes of feeling that needed to be replaced by a different, more democratic emotionality. This re-éducation sentimentale allows for intriguing questions like whether and how it was possible to tell and teach somebody to feel differently. From a different angle,

\footnotetext{
${ }^{6}$ For a similar understanding of 'feeling differently' as oscillating between equality and difference cf. Nay (2013), a title we discovered only after writing the
} first draft of this article. queer and critical race studies have discussed the constitution of minoritarian affiliations through 'negative feelings': melancholia, trauma and suffering can bring out the articulation of political dissent as well as the formation of minoritarian subjectivities through expressions of a difference in feeling (e.g. Ahmed, 2010; Butler, 1997; Cvetkovich, 2003; Love, 2007; Ngai, 2007). Michaelsen's investigation of an LGBT internet campaign in this issue points out that negative feelings can also be mobilised by universalising liberal-capitalist narratives that address potentially everyone's experiences of suffering-while simultaneously eclipsing the particular suffering of minoritarian subjects. Ultimately, this suffering is transformed into optimism, which Michaelsen reads as an attempt to conceal suffering, and hence emotional difference, by referring to a better future of emotional sameness.

Juxtaposing these divergent lines of engaging with feelings as constituting difference signals how a focus might be variously placed on the production of differential-hegemonic and minoritarian-social identities, or on processes of subjectification and de-subjectification. However, feelings need not only be viewed as troubling norms and generating differences, it can also be examined how they mark, intensify or naturalise existing differences. Reddy (2001) has for instance investigated the bourgeoisie's emphasis on their 'authentic' feelings as a marker of the difference established vis-à-vis the nobility's 'artificiality'. In a similar vein, Pernau (2014) has analysed the colonial project of separating 'civilised' from 'barbaric' modes of feeling. Such analyses have proven particularly insightful where they also consider how various lines of differentiation intersect and thus unsettle clear-cut assumptions about who feels in which way (Loos, 2012). Moreover, feelings can be viewed as intensifying or naturalising existing differences as these are embodied. This is particularly obvious when sensuously experienced forms of disgust or aversion express or serve to consolidate racist hierarchies (Gutiérrez-Rodriguez, 2010; Wise, 2010). Economic hierarchies and their links to gender and political inequalities can also be buttressed by emotional practices, which has been explored in the domain of care relations, where 'affective inequalities' (Lynch et al., 2009) can be viewed as a kind of feeling differently that naturalises power relations.

Tracing such intensified differences can also reveal how they are troubled. Trott in this issue reflects on how emotional labour supports social stratification, yet also opens pathways for affectively based organising. He argues that in industries from aviation to retail, differences between high and lower-end production tend to correlate with the distinction Hochschild drew between 'deepacted' emotional labour and 'surface acting': for example, barely disguising emotions like frustration provides customers the feeling of only paying the bare minimum; but, Trott goes on to argue, by organising encounters across such differences, it may become possible to generate more joyful affects that enhance one's power to act.

As this outline signals, setting a focus on the various, often intersecting, ways in which feelings trouble norms, constitute difference and mark, intensify or naturalise differences suggests particular understandings, not only of feelings, but also of difference. Frequently, debates about the 'politics of difference' have revolved around contestations between the positions subjects and places assume and are ascribed to-around what Stuart Hall (1980), drawing on Gramsci, has called the 'war of position'. By and large, these debates have tended to frame differences in terms of discrete, mutually exclusive terms ordered in binary opposition (for critical discussions, see Haraway, 1999; Massey et al., 1999). As a correlate, resistance has been posited in dichotomous opposition to domination. Yet, discussions of difference, division and heterogeneity have also directed attention to the emergence and ordering of nonbinary differences-differences which are 'something' in and of 
themselves, more than just 'different from' something (see e.g. Braidotti, 2005/2006; Massey, 2005), and plural enough not to be reducible to a binary (Sedgwick, 1990). Likewise, resistance and social change have come to be understood not only in terms of direct opposition or through mere inversion of symbolic or political orders, but through such means as hidden transcripts (Scott, 1990), polysemic bricolage (Hebdige, 1979), parody (Butler, 1990), or 'disidentificatory' working on and against ideology from within (Muñoz, 1999), - all of which can be viewed as bearing a potential to reorganise social and cultural structures and premises. From such perspectives, discrete positions and binary oppositions do not necessarily need to be regarded as fictitious, but can be viewed as situated within and emerging from a more complex landscape of non-binary differences. In such a vein, our focus on 'feeling differently' invites nuanced investigations of the ongoing production of differences and their contingent effects, as they variously trouble norms, intensify them or give rise to new ones. Ways of feeling differently, and feelings more generally, are not per se either consolidating or subversive, nor do they imply a homogenous emotional structure or style. They therefore cannot be captured with a single approach to feelings or difference.

\section{The politics of researching feeling differently}

If feeling differently can figure in a range of enabling and disabling processes, inviting a variety of intersecting theoretical approaches, its analysis prompts a series of questions regarding the wider political aims and effects linked with particular research strategies. Representatives of the turn towards affect and emotions have criticized the academic mainstream for disregarding feelings and over-emphasizing the rational (Bondi, 2005; Frevert, 2009; Goodwin et al., 2001). They have often also taken issue with the focus on the semiotic and the discursive that the cultural turn and constructionist paradigms entailed, trying to forge more immediate forms of access to the phenomena they studied (cf. Mazzarella, 2009; Plamper, 2015; Wetherell, 2012). In certain ways, the emotional and affective turns were intertwined with the crisis of the Fordist mode of industrial (re)production framed around the model of the male breadwinner. As the normatively gendered realms of the public-associated with rationality-and private-associated with intimacy-came under pressure, the growth of the service industries simultaneously granted feelings and their performance renewed significance in relation to labour. In this context various socio-political endeavours-from feminism across the ecological movement to various therapeutic approaches-set out to struggle against an over-emphasis on the rational and for an appreciation of the bodily and felt dimensions of subjectivity and relationality (cf. Illouz, 2007).

Research engagements with feelings have thus been associated with political claims that are related to social transformations and contestations. Yet, answers to the question of how to analyse feeling, emotions or affects in politically productive ways have been far from consistent. While some have called for an understanding of the political that cherishes affective and emotional dimensions instead of relying exclusively on rational deliberation and critiques of hegemonic systems of knowledge and power (e.g. Massumi, 2002; Sedgwick, 2003), others have argued that such non-representational strategies depoliticise feelings by disentangling them from the sphere where power can be properly contested-especially the sphere of political deliberation (Barnett, 2008; see also Sharp, 2009). From this point of view, focusing on affect as pre-discursive or pre-cultural can even be considered a means to disguise hierarchies. This applies particularly when an all too simplified understanding of the 'material body' disconnects affect from historically and culturally specific power formations (see the critiques by Ahmed, 2014; Leys, 2011). From this angle, feelings should therefore primarily be considered in close connection to social and cultural structures, as phenomena that are potentially as graspable as any other and that can and need to be processed within critical discourse.

Yet, coming back to the issue of feeling differently, approaches assuming feelings to be fully graspable risk obliterating the ways in which such modes of feeling oscillate ambiguously between the contestation of emotional norms, the dynamics of subjectification and the continuous variation of affect. In particular, engaging with 'feeling differently' invites an interrogation of established forms of striving for social change and highlights the role of feelings as at least partly excessive and contingent phenomena. Such a research endeavour does not necessarily collide with deliberative strategies. Feminist and queer scholars in particular have indicated possibilities for navigating the seeming gap between the unfathomable dimensions of feeling and a politically engaged analysis that effectively counters powerful discourses-for instance, by highlighting "the critical intelligence of affect" (Berlant, 2008: 2; see also Ahmed, 2014; Hemmings, 2012). The Chicago Feel Tank's slogan "Depressed? It might be political!"-not coincidentally reminiscent of the feminist motto about the private being political- serves a similar purpose. This attempt to join the disruptive force of the non-representational with critical perspectives on power has implications not only at the level of analysis, but also at the level of academic writing and research practice (e.g. Bondi, 2005). This involves issues such as how feelings can be textually represented (Dowling, 2012), how researchers can account for the impact of their own feelings on knowledge production (Aurell, 2015; Drozdzewski and Dominey-Howes, 2015), how they should relate with research subjects and which formats they should choose for publishing and discussing their results.

While such efforts indicate ways out of the alleged opposition between the affective and the critical, researchers engaging with 'feeling differently' are also asked to consider how specific approaches privilege certain forms and scales of political intervention. Are affect- and practice-theoretical approaches more prone to tackle the micropolitics of spontaneity and embodied becoming, whereas rules-based perspectives are more relevant to macroforms of organised politics? This also raises the question of what kinds of difference or asymmetry research on 'feeling differently' addresses and how they can be promoted or contested. To what extent, for instance, do analyses of emotional habitus consider issues of cultural capital and class distinction, of racism or of heteronormativity? Do non-representational approaches also consider how the semiotic contents and formats of media displays form part of the affective economies they set out to describe?

In this respect, specific potential resides in attending to the multifarious micro-landscapes of non-binary differences and affiliations that sprawl across the rigid grid of powerful macrodichotomies like male/female, white/black and straight/queer (Massumi, 2002; Sedgwick, 2003), while at the same time not discounting the latter's impact (Haraway, 1999). Attention might be directed at shifting and intersecting scales rather than at just one. The point here is not to pit micro-events against macrostructures, local fuzziness against global order, but rather to trace the intricate ways in which they conjoin and interact. In the debate on the emotional navigation of cultural differences, for example, analyses operating at a large scale tend to focus on stereotyping and intergroup representations, whereby they often reproduce the categories and asymmetries they set out to explore. Such studies mostly argue along the lines of rules-based approaches and concern themselves with patterned forms of emotional behaviours ranging from hate and disgust to empathy and trust (e.g. Hooghe et al., 2009; McAllister and Irvine, 2002). These 
perspectives might be productively complemented by research operating both on even larger scales including colonial power formations, and on a smaller scale that improves our understanding of how racist hierarchies operate on a visceral level (Mai and King, 2009; Wise, 2010).

Another valuable supplement are studies that, by zooming in on the everyday and the sensual, reach across the scales of marketable pluralism and major dichotomies to the scale of minor, intersecting and instable differences, exploring the trajectories of convivial, friendly and joyful forms of becoming (Gilroy, 2004; Wise and Velayutham, 2009; Zembylas, 2015). At the same time, however, it is vital for research on 'feeling differently' to observe how such singularities can assemble into larger-scale formations (Saldanha, 2006), how effects trickle down, as it were, from macro-to microlevels, and how certain phenomena link and jump from one scale to another in a discontinuous manner. A current example for such leaps and short-cuts is the rage circulating in the United States, Europe and elsewhere between public calls for rigid border controls and racist attitudes vented in more private settings, between parliamentary debates about immigration and media representations of conflicts between 'locals' and 'migrants'. These multifarious connections enable rage to switch levels and to re-surface in unexpected places. In this vein, research on 'feeling differently' needs to keep track of larger-scale distributions of fear and resentment, affective manifestations of racism at the micro scale as well as the discontinuous movements between them if it wants to intervene in the ongoing emergence and fixing of specific emotional constellations.

This endeavour ultimately raises the question of how we position ourselves as researchers in relation to the processes and contestations we enquire. Non-representational approaches often highlight the potential of radical excess to subvert the status quo. Yet studies of purposefully developed non-conforming emotional practices point out that such radical gestures can sometimes be adapted to hegemonic procedures. At the same time, rather inconspicuous and unagitated modes of feeling differently can occasionally generate creative turmoil. It might also be vital to attend to negative, seemingly unproductive feelings in order to engage with trauma and build communities of solidarity and care, as queer debates on negative affect have shown. Focusing on the emergence of agentic capacities could ultimately prove more potent than limiting oneself to the paranoid framework of critical suspicion when examining the mechanisms of marginalisation (Sedgwick, 2003). Again, there does not seem to be any universally valid way of politicising excessive or immanent, positive or negative affect. Instead, the polyvalent nature of feeling differently invites the continued interrogation of the power effects going along with our research endeavours. Analyses can move into such a direction by attending to the subversive as well as the conforming features of the phenomena they scrutinise, and by considering the effects of their own representational practices. The same applies to analyses of feelings directed against the oppressive systems of capitalism or heteronormativity as potentially simultaneously underpinning and undermining hegemonic structures. Research on 'feeling differently' can thus complicate all too clear distinctions between cooperation and resistance. Moving between or beyond the poles of rules-based conformity and transgressive subversion-much like Bartelby's formula "I would prefer not to" (Agamben, 1999: 19)— analyses might enrich their political impact by highlighting the contingent, yet not arbitrary, effects of their own intervention as well as those of any other action or encounter.

In reaching well beyond the confines of the political in a more traditional sense of rational deliberation, the various approaches we have discussed demonstrate how specific understandings of feeling and difference equip research on 'feeling differently' with a whole range of divergent political implications. Yet our aim here has not been to privilege one approach over another. The discussion rather sought to show that decisions to employ one approach or the other or any combination of them lends the analysis a specific political thrust. Settling on a certain strategy is therefore not a mere matter of taste, but one that matters. As Haraway remarked: "[s]ome differences are playful; some are poles of world historical systems of domination. 'Epistemology' is about knowing the difference" (Haraway, 1999: 281). Especially in debates emphasising the 'ontological', this epistemological issue remains vital. We hope that the following articles-among many other things-also shed new light on how differences come to matter through particular approaches to the study of feelings.

\section{Acknowledgements}

We would like to thank Beate Binder and the journal editors for their insightful and detailed comments on earlier drafts.

\section{References}

Agamben, Giorgio, 1999. Bartelby, or on contingency. In: Agamben, Giorgio, Potentialities (Eds.), Collected Essays in Philosophy, Edited and Translated by Daniel Heller-Roazen. Stanford University Press, Stanford, pp. 243-271.

Ahmed, Sara, 2010. The Promise of Happiness. Duke University Press, Durham. Ahmed, Sara, 2014. The Cultural Politics of Emotion, second ed. Routledge, New York.

Althoff, Gerd, 1998. Ira regis: prolegomena to a history of Royal anger. In: Rosenwein, Barbara H. (Ed.), Anger's Past: The Social Uses of an Emotion in the Middle Ages. Cornell University Press, Ithaca, pp. 59-74.

Amin, Ash, Thrift, Nigel, 2013. Arts of the Political: New Openings for the Left. Duke University Press, Durham.

Anderson, Ben, 2014. Encountering Affect: Capacities, Apparatuses, Conditions. Ashgate, Farnham.

Anderson, Ben, Harrison, Paul (Eds.), 2010. Taking-Place: Non-Representational Theories and Geography. Ashgate, Farnham.

Aurell, Jaume, 2015. Making history by contextualizing oneself: autobiography as historiographical intervention. Hist. Theory 54 (2), 244-268. http:// dx.doi.org/10.1111/hith.10756.

Barnett, Clive, 2008. Political affects in public space: normative blind-spots in nonrepresentational ontologies. Trans. Inst. Br. Geogr. 33 (2), 186-200. http:// dx.doi.org/10.1111/j.1475-5661.2008.00298.x.

Benei, Véronique, 2008. Schooling Passions: Nation, History, and Language in Contemporary Western India. Stanford University Press, Stanford.

Berlant, Lauren, 2008. The Female Complaint: The Unfinished Business of Sentimentality in American Culture. Duke University Press, Durham.

Berlant, Lauren, 2011. Cruel Optimism. Duke University Press, Durham.

Bissell, David, 2015. How environments speak: everyday mobilities, impersonal speech and the geographies of commentary. Soc. Cult. Geogr. 16 (2), 146-164 http://dx.doi.org/10.1080/14649365.2014.958520.

Bondi, Liz, 2005. The place of emotions in research: from partitioning emotion and reason to the emotional dynamics of research relationships. In: Davidson, Joyce Bondi, Liz, Smith, Mick (Eds.), Emotional Geographies. Ashgate, Aldershot pp. 231-246.

Bondi, Liz, 2014. Feeling insecure: a personal account in a psychoanalytic voice. Soc. Cult. Geogr. 15 (3), 332-350. http://dx.doi.org/10.1080/14649365.2013.864783.

Braidotti, Rosi, 2005/2006. Affirming the Affirmative: on Nomadic Affectivity. Rhizomes (11/12). http://www.rhizomes.net/issue11/braidotti.html.

Braunmühl, Caroline, 2012. Theorizing emotions with Judith Butler: within and beyond the courtroom. Rethink. Hist. 16 (2), 221-240. http://dx.doi.org $10.1080 / 13642529.2012 .681192$.

Briggs, Jean L., 1970. Never in Anger: Portrait of an Eskimo Family. Harvard University Press, Cambridge, MA.

Brinkema, Eugenie, 2014. The Forms of the Affects. Duke University Press, Durham.

Brown, Gavin, Pickerill, Jenny, 2009. Space for emotion in the spaces of activism. Emotion, Space Soc. 2 (1), 24-35. http://dx.doi.org/10.1016/ j.emospa.2009.03.004.

Burkitt, Ian, 1997. Social relationships and emotions. Sociology 31 (1), 37-55. http:/ dx.doi.org/10.1177/0038038597031001004.

Butler, Judith, 1990. Gender Trouble: Feminism and the Subversion of Identity Routledge, New York.

Butler, Judith, 1997. The Psychic Life of Power: Theories in Subjection. Stanford University Press, Stanford.

Clough, Patricia Ticineto, Halley, Jean (Eds.), 2007. The Affective Turn: Theorizing the Social. Duke University Press, Durham.

Connolly, William E., 2011. The complexity of intention. Crit. Inq. 37 (4), 791-798 http://dx.doi.org/10.1086/660993.

Cvetkovich, Ann, 2003. An Archive of Feelings: Trauma, Sexuality, and Lesbian 
Public Cultures. Duke University Press, Durham.

Dinshaw, Carolyn, 2007. Temporalities. In: Strohm, Paul (Ed.), Middle English. Oxford University Press, Oxford, pp. 107-123.

Dowling, Emma, 2012. The waitress: on affect, method and (re)presentation. Cult Stud. $<=>$ Crit. Methodol. 12 (2), 109-117. http://dx.doi.org/10.1177 1532708611435215.

Dowling Emma, Nunes Rodrigo and Trott Ben, (Eds.), Immaterial and affective labour: Explored, Ephemera 7 (1), 2007 http://www.ephemerajournal.org/sites default/files/pdfs/7-1ephemera-feb07.pdf.

Drozdzewski, Danielle, Dominey-Howes, Dale, 2015. Research and trauma: understanding the impact of traumatic content and places on the researcher. Emotions, Space Soc. 17, 17-21. http://dx.doi.org/10.1016/j.emospa.2015.09.001.

Eitler, Pascal, Scheer, Monique, 2009. Emotionengeschichte als Körpergeschichte: eine heuristische Perspektive auf religiöse Konversionen im 19. und 20. Jhd. Gesch. Ges. 35 (2), 282-313.

Fassin, Didier, 2005. Compassion and repression: the moral economy of immigration policies in France. Cult. Anthropol. 20 (3), 362-387.

Frevert, Ute, 2009. Was haben Gefühle in der Geschichte zu suchen? Gesch. Ges. 35 (2), 183-208. http://dx.doi.org/10.13109/gege.2009.35.2.183.

Gammerl, Benno, 2012. Emotional styles: concepts and challenges. Rethink. Hist. 16 (2), 161-175. http://dx.doi.org/10.1080/13642529.2012.681189.

Gilroy, Paul, 2004. After Empire: Melancholia or Convivial Culture? Routledge Abingdon.

Goodwin, Jeff, Jasper, James M., Polletta, Francesca, 2001. Passionate Politics: Emotions and Social Movements. University of Chicago Press, Chicago.

Gould, Deborah B., 2009. Moving Politics: Emotion and ACT UP's Fight against AIDS University of Chicago Press, Chicago.

Gregg, Melissa, Seigworth, Gregory J. (Eds.), 2010. The Affect Theory Reader. Duke University Press, Durham.

Grossberg, Lawrence, 2010. Affect's future: rediscovering the virtual in the actual. In: Gregg, Melissa, Seigworth, Gregory J. (Eds.), The Affect Theory Reader. Duke University Press, Durham, pp. 309-338.

Gutiérrez-Rodriguez, Encarnación, 2010. Migration, Domestic Work and Affect: A Decolonial Approach on Value and the Feminization of Labor. Routledge, New York.

Häberlen, Joachim, Spinney, Russell, 2014. Introduction. Contemp. Eur. Hist. 23 (4) 489-503.

Hall, Stuart, 1980. Cultural studies: two paradigms. Media, Cult. Sci. 2 (1), 57-72 http://dx.doi.org/10.1177/016344378000200106.

Haraway, Donna J., 1999. A cyborg manifesto. In: During, Simon (Ed.), The Cultural Studies Reader, second ed. Routledge, London, pp. 271-291.

Hebdige, Dick, 1979. Subculture: The Meaning of Style. Routledge, London.

Hemmings, Clare, 2012. Affective solidarity: feminist reflexivity and political transformation. Fem. Theory 13 (2), 147-161. http://dx.doi.org/10.1177/146470 0112442643.

Hochschild, Arlie Russell, 1979. Emotion work, feeling rules, and social structure Am. J. Sociol. 85 (3), 551-575.

Hollan, Douglas, 1988. Staying 'cool' in Toraya: informal strategies for the management of anger and hostility in a nonviolent society. Ethos 16 (1), 52-72.

Holt, Louise, Bowlby, Sophie, Lea, Jennifer, 2013. Emotions and the habitus: young people with socio-emotional differences (re)producing social, emotional and cultural capital in family and leisure space-times. Emotion, Space Soc. 9, 33-41. http://dx.doi.org/10.1016/j.emospa.2013.02.002.

Hooghe, Marc, Reeskens, Tim, Stolle, Dietlind, Trappers, Ann, 2009. Ethnic diversity and generalized trust in Europe: a cross-national multilevel study. Comp. Polit. Stud. 42 (2), 198-223. http://dx.doi.org/10.1177/0010414008325286.

Hunt, Lynn, 2008. Inventing Human Rights: A History. Norton, New York

Hutta, J[an] S[imon], 2015. The affective life of semiotics. Geogr. Helvetica 70 (4) 295-309. http://dx.doi.org/10.5194/gh-70-295-2015.

Illouz, Eva, 2007. Cold Intimacies: The Making of Emotional Capitalism. Polity Press, London.

Timm Knudsen, Britta, Stage, Carsten, 2012. Contagious bodies: an investigation of affective and discursive strategies in contemporary online activism. Emot. Space Soc. 5 (3), 148-155. http://dx.doi.org/10.1016/j.emospa.2011.08.004.

Timm Knudsen, Britta, Stage, Carsten, 2015. Introduction: affective methodologies. In: Timm Knudsen, Britta, Stage, Carsten (Eds.), Affective Methodologies: Developing Cultural Research Strategies for the Study of Affect. Palgrave Macmillan, New York, pp. 1-22.

Leys, Ruth, 2011. The turn to affect: a critique. Crit. Inq. 37 (3), 434-472. http:/ dx.doi.org/10.1086/659353.

Lim, Jason, 2007. Queer critique and the politics of affect. In: Browne, Kath, Lim, Jason, Brown, Gavin (Eds.), Geographies of Sexualities: Theory, Practices and Politics. Ashgate, Aldershot, pp. 53-67.

Loos, Tamara, 2012. Besmirched with blood: an emotional history of transnational romance in colonial Singapore. Rethink. Hist. 16 (2), 199-220. http://dx.doi.org $10.1080 / 13642529.2012 .681191$.

Lorimer, Hayden, 2008. Cultural geography: non-representational conditions and concerns. Prog. Hum. Geogr. 32 (4), 551-559. http://dx.doi.org/10.1177 0309132507086882.

Love, Heather, 2007. Feeling Backward: Loss and Politics of Queer History. Harvard University Press, Cambridge, MA

Lutz, Catherine A., Abu-Lughod, Lila (Eds.), 1990. Language and the Politics of Emotion. Cambridge University Press, Cambridge.

Lynch, Kathleen, Baker, John, Lyons, Maureen, 2009. Affective Equality: Love, Care and Injustice. Palgrave Macmillan, Basingstoke.
Mai, Nicola, King, Russell, 2009. Love, sexuality and migration: mapping the issue(s). Mobilities 4 (3), 295-307. http://dx.doi.org/10.1080/ 17450100903195318

Massey, Doreen, 2005. For Space. Sage, London.

Massey, Doreen, Allen, John, Sarre, Phil (Eds.), 1999. Human Geography Today. Polity, Cambridge.

Massumi, Brian, 2002. Parables for the Virtual: Movement, Affect, Sensation. Duke University Press, Durham.

Mazzarella, William, 2009. Affect: what is it good for? In: Dube, Saurabh (Ed.), Enchantments of Modernity: Empire, Nation, Globalization. Routledge, London, pp. $291-309$.

McAllister, Gretchen, Irvine, Jacqueline Jordan, 2002. The role of empathy in teaching culturally diverse students: a qualitative study of teachers' beliefs. J. Teach Educ. 53 (5), 433-443. http://dx.doi.org/10.1177/002248702237397.

Muñoz, José Esteban, 1999. Disidentifications: Queers of Color and the Performance of Politics. University of Minnesota Press, Minneapolis.

Nay, Eveline Y., 2013. Feeling Differently: affektive Politiken der Gleichheit in Differenz. In: Grisard, Dominique, Jäger, Ulle, König, Tomke (Eds.), Verschieden Sein: Nachdenken über Geschlecht und Differenz. Ulrike Helmer Verlag, Sulzbach/ Taunus, pp. 281-294.

Newman, Sally, 2012. The freshman malady': rethinking the ontology of the 'crush. Rethink. Hist. 16 (2), 279-301. http://dx.doi.org/10.1080/13642529. 2012.681195.

Ngai, Sianne, 2007. Ugly Feelings. Harvard University Press, Cambridge, MA.

Parkinson, Anna M., 2015. An Emotional State: The Politics of Emotion in Postwar West German Culture. University of Michigan Press, Ann Arbor.

Pernau, Margrit, 2014. Civility and barbarism: emotion as criteria of difference. In: Frevert, Ute, et al. (Eds.), Emotional Lexicons: Continuity and Change in the Vocabulary of Feeling 1700-2000. Oxford University Press, Oxford, pp. 230-259.

Petersen, Roger D., 2011. Western Intervention in the Balkans: The Strategic Use of Emotion in Conflict. Cambridge University Press, Cambridge.

Pile, Steve, 2010. Emotions and affect in recent human geography. Trans. Inst. Br. Geogr. 35 (1), 5-20. http://dx.doi.org/10.1111/j.1475-5661.2009.00368.x.

Plamper, Jan, 2015. The History of Emotions: An Introduction. Oxford University Press, Oxford.

Puar, Jasbir K., 2007. Terrorist Assemblages: Homonationalism in Queer Times. Duke University Press, Durham.

Reckwitz, Andreas, 2016. Practices and their affects. In: Hui, Allison, Schatzki, Theodore, Shove, Elisabeth (Eds.), The Nexus of Practices: Connections, Constellations, Practitioners. Routledge, London, pp. 114-125.

Reddy, William M., 2001. The Navigation of Feeling: A Framework for the History of Emotions. Cambridge University Press, Cambridge.

Rosenwein, Barbara H., 2006. Emotional Communities in the Early Middle Ages, Cornell University Press, Ithaca and London.

Saldanha, Arun, 2006. Reontologising race: the machinic geography of phenotype. Environ. Planning D: Soc. Space 24 (1), 9-24. http://dx.doi.org/10.1068/d61j.

Scheer, Monique, 2012. Are emotions a kind of practice (and is that what makes them have a history)? A Bourdieuian approach to understanding emotion. Hist. Theory 51 (2), 193-220. http://dx.doi.org/10.1111/j.1468-2303. 2012.00621.x.

Scott, James C., 1990. Domination and the Arts of Resistance: Hidden Transcripts. Yale University Press, New Haven.

Sedgwick, Eve Kosofsky, 1990. Epistemology of the Closet. University of California Press, Berkeley.

Sedgwick, Eve Kosofsky, 2003. Touching Feeling: Affect, Pedagogy, Performativity. Duke University Press, Durham.

Sharp, Joanne, 2009. Geography and gender: what belongs to feminist geography? Emotion, power and change. Prog. Hum. Geogr. 33 (1), 74-80. http://dx.doi.org/ $10.1177 / 0309132508090440$.

Shouse, Eric, 2005. Feeling, Emotion, Affect. M/C Journal 8(6), W/o Pages. Available online at: http://journal.media-culture.org.au/0512/03-shouse.php. checked on 10 April 2017.

Sibley, David, 1999. Creating geographies of difference. In: Massey, Doreen, Allen, John, Sarre, Phil (Eds.), Human Geography Today. Polity, Cambridge, pp. $115-128$

Spinoza, Benedict de, 1996. Ethics. Penguin Books. London and New York.

Stavrakakis, Yannis, 2010. Discourse, affect, jouissance: psychoanalysis, political theory and artistic practices. In: Paper presented at Art \& Desire Seminars. http://www.sanatvearzu.net/pdf/IIZS-Stavrakakis.pdf.

Stearns, Peter N., Stearns, Carol Z., 1985. Emotionology: clarifying the history of emotions and emotional standards. Am. Hist. Rev. 90 (4), 813-836.

Thrift, Nigel, 2007. Non-representational Theory: Space, Politics, Affect. Routledge, London.

Wetherell, Margaret, 2012. Affect and Emotion: A New Social Science Understanding. Sage, Los Angeles and others.

Wise, Amanda, 2010. Sensuous multiculturalism: emotional landscapes of interethnic living in Australian suburbia. J. Ethn. Migr. Stud. 36 (6), 917-937. http://dx.doi.org/10.1080/13691831003643355.

Wise, Amanda, Velayutham, Selvaraj, 2009. Everyday Multiculturalism. Palgrave Macmillan, Basingstoke.

Wylie, John, 2005. A single days's walking: narrating self and landscape on the South West Coast Path. Trans. Inst. Br. Geogr. 30 (2), 234-247. http:// dx doi.org/10.1111/j.1475-5661.2005.00163.x.

Zembylas, Michalinos, 2015. Rethinking race and racism as technologies of affect: theorizing the implications for anti-racist politics and practice in education. 
Race Ethn. Educ. 18 (2), 145-162. http://dx.doi.org/10.1080/ 13613324.2014.946492.

Dr. Benno Gammerl

Center for the History of Emotions, Max Planck Institute for Human Development, Lentzeallee 94, 14195 Berlin, Germany E-mail address: gammerl@mpib-berlin.mpg.de.

Dr. Jan Simon Hutta Department of Cultural Geography, University of Bayreuth, Universitaetsstr. 30, 95440 Bayreuth, Germany

E-mail address: Jan.Hutta@uni-bayreuth.de.
Prof. Dr. Monique Scheer Ludwig Uhland Institute for Historical and Cultural Anthropology, University of Tuebingen, Burgsteige 11, Schloss, 72074, Tuebingen, Germany

${ }^{*}$ Corresponding author. E-mail address: monique.scheer@uni-tuebingen.de (M. Scheer).

7 November 2016 Available online $\mathrm{xxx}$

Please cite this article in press as: Gammerl, B., et al., Feeling differently: Approaches and their politics, Emotion, Space and Society (2017), http://dx.doi.org/10.1016/j.emospa.2017.07.007 